NASA/TM-2004-213055

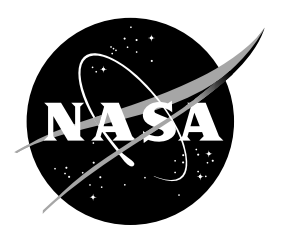

\title{
Characterization of $\mathrm{C}$ /Enhanced $\mathrm{SiC}$ Composite During Creep-Rupture Tests Using an Ultrasonic Guided Wave Scan System
}

Don J. Roth and Michael J. Verrilli

Glenn Research Center, Cleveland, Ohio

Richard E. Martin and Laura M. Cosgriff

Cleveland State University, Cleveland, Ohio 
Since its founding, NASA has been dedicated to the advancement of aeronautics and space science. The NASA Scientific and Technical Information (STI) Program Office plays a key part in helping NASA maintain this important role.

The NASA STI Program Office is operated by Langley Research Center, the Lead Center for NASA's scientific and technical information. The NASA STI Program Office provides access to the NASA STI Database, the largest collection of aeronautical and space science STI in the world. The Program Office is also NASA's institutional mechanism for disseminating the results of its research and development activities. These results are published by NASA in the NASA STI Report Series, which includes the following report types:

- $\quad$ TECHNICAL PUBLICATION. Reports of completed research or a major significant phase of research that present the results of NASA programs and include extensive data or theoretical analysis. Includes compilations of significant scientific and technical data and information deemed to be of continuing reference value. NASA's counterpart of peerreviewed formal professional papers but has less stringent limitations on manuscript length and extent of graphic presentations.

- TECHNICAL MEMORANDUM. Scientific and technical findings that are preliminary or of specialized interest, e.g., quick release reports, working papers, and bibliographies that contain minimal annotation. Does not contain extensive analysis.

- CONTRACTOR REPORT. Scientific and technical findings by NASA-sponsored contractors and grantees.
- CONFERENCE PUBLICATION. Collected papers from scientific and technical conferences, symposia, seminars, or other meetings sponsored or cosponsored by NASA.

- SPECIAL PUBLICATION. Scientific, technical, or historical information from NASA programs, projects, and missions, often concerned with subjects having substantial public interest.

- TECHNICAL TRANSLATION. Englishlanguage translations of foreign scientific and technical material pertinent to NASA's mission.

Specialized services that complement the STI Program Office's diverse offerings include creating custom thesauri, building customized databases, organizing and publishing research results ... even providing videos.

For more information about the NASA STI Program Office, see the following:

- Access the NASA STI Program Home Page at http://www.sti.nasa.gov

- E-mail your question via the Internet to help@sti.nasa.gov

- Fax your question to the NASA Access Help Desk at 301-621-0134

- Telephone the NASA Access Help Desk at 301-621-0390

- Write to:

NASA Access Help Desk

NASA Center for AeroSpace Information 7121 Standard Drive

Hanover, MD 21076 
NASA/TM-2004-213055

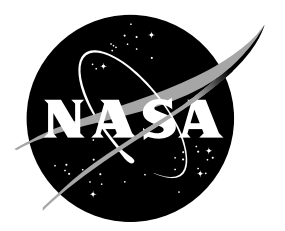

\section{Characterization of $\mathrm{C}$ /Enhanced $\mathrm{SiC}$ Composite During Creep-Rupture Tests Using an Ultrasonic Guided Wave Scan System}

Don J. Roth and Michael J. Verrilli

Glenn Research Center, Cleveland, Ohio

Richard E. Martin and Laura M. Cosgriff

Cleveland State University, Cleveland, Ohio

Prepared for the

28th Annual International Conference and Exposition on Advanced Ceramics and Composites sponsored by the American Ceramic Society

Cocoa Beach, Florida, January 25-30, 2004

National Aeronautics and

Space Administration

Glenn Research Center 
Available from

NASA Center for Aerospace Information 7121 Standard Drive

Hanover, MD 21076
National Technical Information Service 5285 Port Royal Road Springfield, VA 22100

Available electronically at http://gltrs.grc.nasa.gov 


\title{
Characterization of C/Enhanced SiC Composite During Creep-Rupture Tests Using an Ultrasonic Guided Wave Scan System
}

\author{
Don J. Roth* and Michael J. Verrilli \\ National Aeronautics and Space Administration \\ Glenn Research Center \\ Cleveland, Ohio 44135 \\ Richard E. Martin and Laura M. Cosgriff \\ Cleveland State University \\ Cleveland, Ohio 44115
}

\section{Summary}

An ultrasonic guided wave scan system was used to nondestructively monitor damage over time and position in a C/enhanced $\mathrm{SiC}$ sample that was creep tested to failure at $1200{ }^{\circ} \mathrm{C}$ in air at a stress of $69 \mathrm{MPa}(10 \mathrm{ksi})$. The use of the guided wave scan system for mapping evolving oxidation profiles (via porosity gradients resulting from oxidation) along the sample length and predicting failure location was explored. The creep-rupture tests were interrupted for ultrasonic evaluation every two hours until failure at $\sim 17.5$ cumulative hours.

\section{Introduction}

Ceramic matrix composites (CMC) are being developed for advanced aerospace propulsion applications in order to save weight, to improve reuse capability, and to increase performance. $\mathrm{C} / \mathrm{SiC}$ materials have shown some promise in these applications but are extremely susceptible to oxidation damage. C/Enhanced SiC (the "enhancement" is in boron carbide, which is put in the composite matrix in order to protect the carbon fibers from oxidation) have shown increased lifetimes over the conventional $\mathrm{C} / \mathrm{SiC}$ materials. ${ }^{2,3} \mathrm{C} / \mathrm{SiC}$ specimens of the dogbone geometry ${ }^{4}$ utilized in this study and tested under rupture conditions in air at $1200{ }^{\circ} \mathrm{C}$ fail outside of the gage length, ${ }^{5}$ in the thermal gradient region between the heated gage section and the grip section held in the water-cooled test machine grips. Further, it has been shown in the C/enhanced $\mathrm{SiC}$ material that oxidation damage occurring under stressed oxidation conditions and leading to specimen failure occurs primarily in the thermal gradient region., ${ }^{2,3}$ The reasons for this are as follows. Matrix microcracks are formed upon cooling during composite processing at around $1200{ }^{\circ} \mathrm{C}$ due to the CTE mismatch between the $\mathrm{C}$ fibers and the SiC matrix. Crack opening is greater in the cooler thermal gradient region than in the hot gage section, resulting in an easier path for oxygen to be transported to the fibers. Also, the matrix enhancement is more effective in preventing $\mathrm{C}$ oxidation at $1200^{\circ} \mathrm{C}$ than at the lower temperatures of the thermal gradient section. Under creep-type conditions, it would be important for NDE (nondestructive evaluation) methods to be able to track oxidation damage spatially as a function of creep time in order to predict degradation rate as a function of sample position and also to predict ultimate failure location. ${ }^{1}$

Distributed micro-damage in CMCs has proven difficult to characterize by conventional NDE methods due to the complex micro- and macro-structure that tends to be a masking agent for all but significant, discrete flaws. Oxidation in $\mathrm{C} / \mathrm{SiC}$ falls in the category of distributed microdamage and leads to porosity variations as the fibers essentially disappear due to the oxidation. One method showing

* Phone: 216-433-6017; Fax: 216-433-8300; E-mail: donald.j.roth@nasa.gov 
promise for characterizing distributed microdamage is the ultrasonic guided wave technique.$^{6-9}$ In particular for CMCs, prior studies conducted at NASA GRC have shown ultrasonic guided waves to be successful for characterizing matrix cracking and stiffness degradation in SiC/SiC materials. Advantages of the guided wave technique include 1) the sample under test does not have to be immersed in fluid (as for most conventional ultrasonic characterization), 2) the method requires access to only one side of the sample, and 3) the method is potentially applicable to components with curved surfaces. This article discusses the use of an ultrasonic guided wave scan system to nondestructively monitor damage over time and position in a C/enhanced $\mathrm{SiC}$ sample that was creep tested to failure. In particular, the use of the guided wave scan system for mapping evolving oxidation profiles along the sample length (via porosity gradients resulting from oxidation) and predicting failure location is explored. The results from one sample are presented in order to study possible trends. A future article will discuss results from four other samples cut from the same block of material and identically-tested.

\section{Experimental}

\section{Material}

The material evaluated in this study was a C/Enhanced SiC material manufactured by GE Power Systems Composites. The CVI SiC matrix is reinforced by a [0/90] two-dimensional plain weave fabric of T-300 carbon fibers. The fiber coating was pyrolytic carbon and the matrix enhancement is boron carbide. The composite had 26 plies and a fiber volume fraction of $46 \%$. After machining from plates, specimens were seal coated with CVI SiC.

\section{Creep Rupture Testing}

Creep (stressed oxidation) tests were conducted at $1200{ }^{\circ} \mathrm{C}$ using a stress of $69 \mathrm{MPa}$ (10 ksi) with water-cooled grips. The creep tests were interrupted every two hours until failure which occurred at $\sim 17.5$ cumulative hours. Elastic modulus was calculated from the ramp-up portion of stress-strain curves at each 2-hour interval.

\section{Guided Wave Method}

The guided wave method is a single-sided technique with the basic measurement employing separated sending and receiving ultrasonic transducers at normal incidence to the sample similar to the acousto-ultrasonic method ${ }^{6,7}$ (fig. 1). The material between the sending and receiving transducers is interrogated. The transducers are coupled to the sample with elastic pads when a measurement is made. The guided wave method discussed in this article utilizes the total (multi-mode) ultrasonic response, does so in a scanning configuration, and employs specialized signal processing routines to extract parameters of the time- and frequency-domain signals. ${ }^{8}$ These parameters have proven to be sensitive to changes in microstructural conditions and to the presence of defects, ${ }^{6-8}$ and appear promising at monitoring degradation in CMCs. ${ }^{9}$ Ultrasonic guided waves through the material thickness are generated when the ultrasonic wavelength is on the order of the thickness of the material being interrogated. The key factor in multi-mode ultrasonic guided wave interrogation is that the relationship between the ultrasonic wavelength $(\lambda)$ and material thickness $(h)$ results in a diffuse field of multiple 


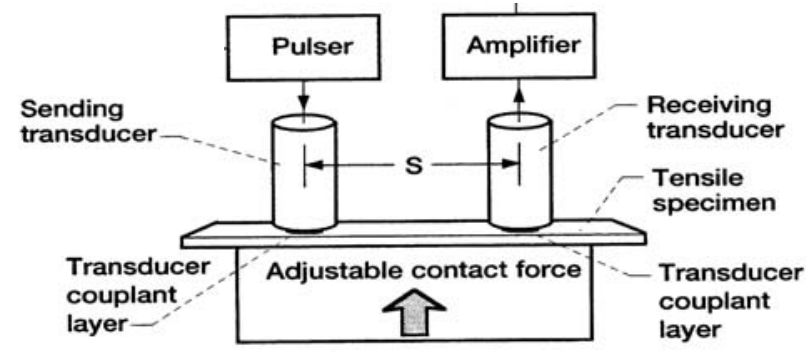

Figure 1. Schematic of multi-mode ultrasonic guided wave experimental setup. $\mathrm{S}=$ distance between sending and receiving transducers.

plate wave modes. ${ }^{6,10}$ Although guided wave techniques are commonly used so scanning can be eliminated, applying the guided wave technique in the scanning mode likely allows a more precise characterization (location, size, shape) of defect conditions.

Broadband $1 \mathrm{MHz}$ ultrasonic transducers were employed to interrogate the C/enhanced SiC creep sample. The distance between sending and receiving transducers was $2.5 \mathrm{~cm}$. Analog-to-digital sampling rate was $10 \mathrm{MHz}$. 14-bit analog-to-digital voltage resolution was employed. A measurement was made (contact load $=3.63 \pm 0.23 \mathrm{~kg}$ [ $8 \pm 0.5 \mathrm{lb}]$ ), the sender-receiver pair was lifted, moved to the next location, lowered to be in contact with the sample, and another measurement made. This routine was repeated such that raster scans were performed over a 25 by 5 array of points with scan increments in the $\mathrm{x}$ - and $\mathrm{y}$-directions equal to 5 and $2 \mathrm{~mm}$, respectively. Ultrasonic parameters calculated from the raw ultrasonic waves at each scan location were plotted at the location of the sending transducer. Three to four scans were run at each creep test interruption and data was statistically analyzed for mean and standard deviation.

The ultrasonic parameter thought initially to be of primary interest in this study was centroid mean time $\langle t\rangle$. This parameter denotes the time demarcating the location of ultrasonic energy balance and is calculated according to

$$
\langle t\rangle=\frac{\int_{t_{a}}^{t_{b}}|\varphi(f, t)|^{2} t d t}{\int_{t_{a}}^{t_{b}}|\varphi(f, t)|^{2} d t}
$$

where $t_{a}$ and $t_{b}$ are the starting and ending times for the integration and $\varphi(f, t)$ is the time domain waveform whose frequency components may vary as a function of time. Integrations are done over the entire captured waveform in this study. $\langle t\rangle$ has shown sensitivity to porosity variations in $\mathrm{SiC} / \mathrm{SiC}$ materials; ${ }^{8}$ this is not surprising as time-of-flight-based ultrasonic parameters such as ultrasonic velocity have historically shown sensitivity to porosity variation in materials. ${ }^{11}$ Thus, it seemed plausible to examine this parameter for characterizing the $1200{ }^{\circ} \mathrm{C}$ oxidation damage profile in the C/enhanced SiC materials, where towards the end of the lifetime, increased porosity would be expected to be seen outside of the gage section as compared to the rest of the sample due to the preferential oxidation. ${ }^{2}$ Other parameters analyzed include initial decay energy $(K)$ (a measure of initial internal ultrasonic absorption by material), zeroth moment $\left(M_{0}\right)$ (a measure of total ultrasonic energy in the material), and centroid frequency (the frequency demarcating the location of ultrasonic energy balance). All of these parameters 
have shown promise for detecting flaws and changing microstructural conditions in CMCs. ${ }^{8} M_{0}$ is calculated according to

$$
M_{0}=\int_{f_{\text {low }}}^{f_{\text {high }}} S(f) d f
$$

where $S(f)$ is the power spectral density, and $f_{\text {low }}$ and $f_{\text {high }}$ are the frequency bounds of integration. Centroid frequency $\left(f_{c}\right)$, analogous to centroid mean time but calculated in the frequency domain using the power spectral density of the time domain waveform, is calculated according to

$$
f_{c}=\frac{\int_{f_{\text {low }}}^{f_{\text {high }}} S(f) f d f}{\int_{f_{\text {low }}}^{f_{\text {high }}} S(f) d f}
$$

The calculation of initial decay energy is fairly complicated and is explained in detail elsewhere. ${ }^{6}$

\section{Results and Discussion}

\section{UT Parameters as a Function of Lineal Spatial Location and Creep Hours}

Figures 2 to 5 show normalized (to as-received measurement) values for $\langle t\rangle, f_{c}$, and $M_{0}$ respectively, as a function of creep hours and scan (sending transducer) location along the center line of the sample. By normalizing to the as-received value, percent changes from as-received value are easily evaluated. Standard deviations, not shown, are on the order of $5 \%$ or less for these parameters. In figure 2, normalized $\langle t\rangle$ line profiles from 8 to 16 hours show $\sim 20$ to $40 \%$ higher values at the thermal gradient regions (sending transducer position $\sim 3$ and $\sim 8.5 \mathrm{~cm}$ ) versus the center possibly indicating a difference in porosity between these areas. Average values calculated from all positions show a primarily increasing trend with increasing creep hours from 2 to 14 hours followed by a drop at 16 hours (fig. 3). The increasing trend would be consistent with an increase in overall porosity with increasing oxidation damage while the drop at 16 hours is not as yet explained. Prior studies have clearly indicated the oxidation damage (and resulting increase in pores) in the thermal gradient region. ${ }^{2}$ Porosity profiles from destructive examination of this sample were expected to be consistent with those seen in prior studies. However, from both optical and SEM examinations of this sample, it was not possible to conclude that there was greater pore fraction at the eventual failure location and unfailed thermal gradient region versus that at the center region (fig. 4). As previously mentioned, the matrix enhancement is more effective in preventing $\mathrm{C}$ oxidation at $1200{ }^{\circ} \mathrm{C}$ (center region) than at the lower temperatures $\left(\sim 80{ }^{\circ} \mathrm{C}\right)$ of the thermal gradient section. However, oxygen content (indicating oxidation) was observed at both the center region and failure location (at shallow void areas and bordering voids) using energy-dispersive spectrometry during SEM examination (fig. 5). Quantifying the relative amounts of oxygen at the different locations was also inconclusive using electron microprobe oxygen mapping of major portions of entire crosssections. However, microprobe examinations were performed at only two cross-sections due to time and cost limitations (more details are presented in the appendix). 


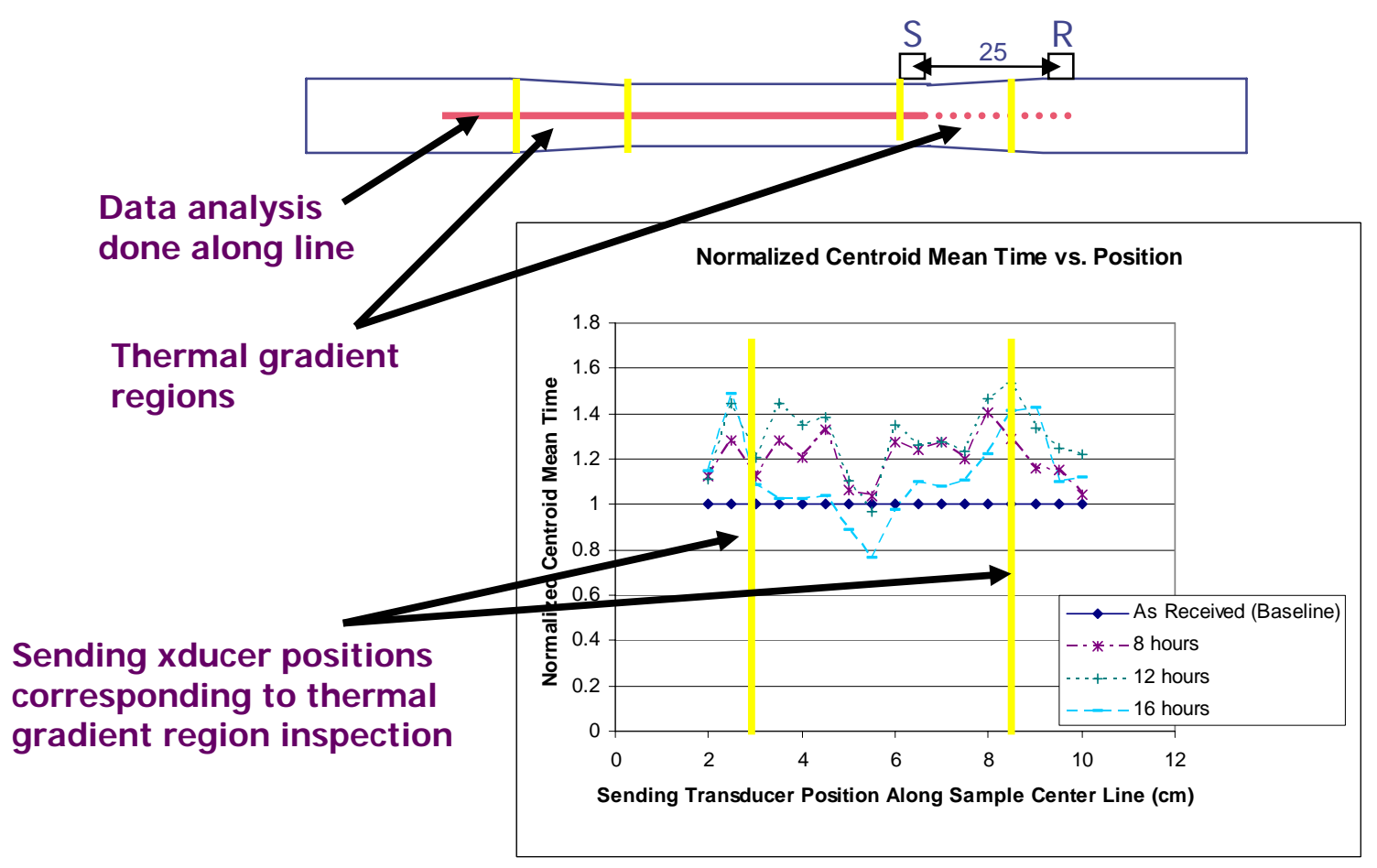

Figure 2. Normalized Centroid Mean Time as a function of creep hours and locations along the center line of the sample.

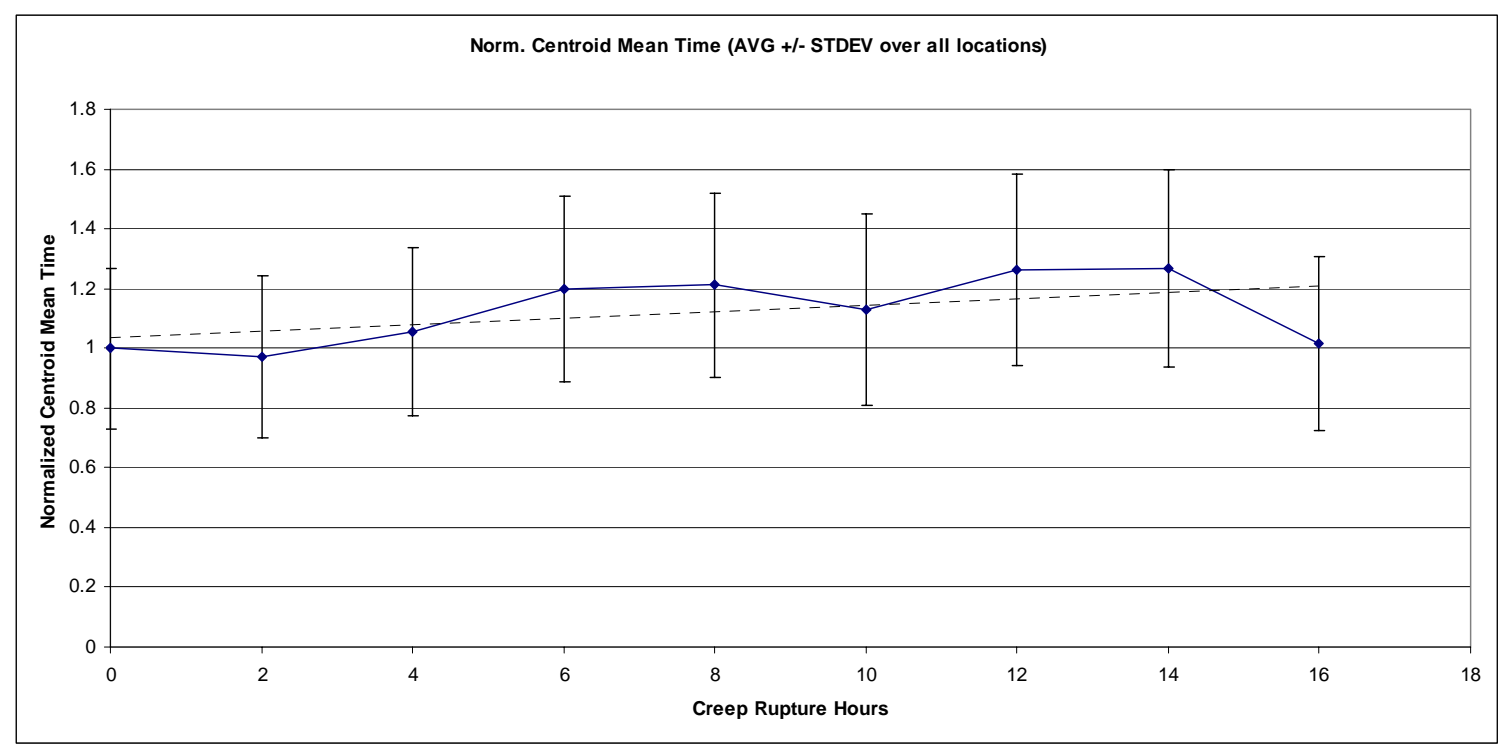

Figure 3. Normalized Centroid Mean Time as a function of creep hours. Each point is the average \pm standard deviation of values at all locations along the center line of the sample.

The dashed line is a linear regression trend line showing increasing trend. 


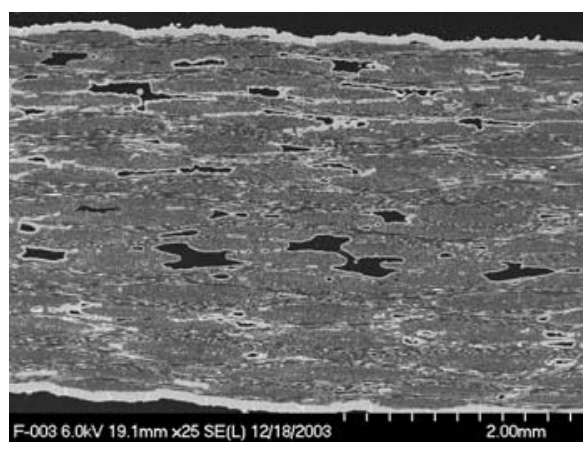

(a)

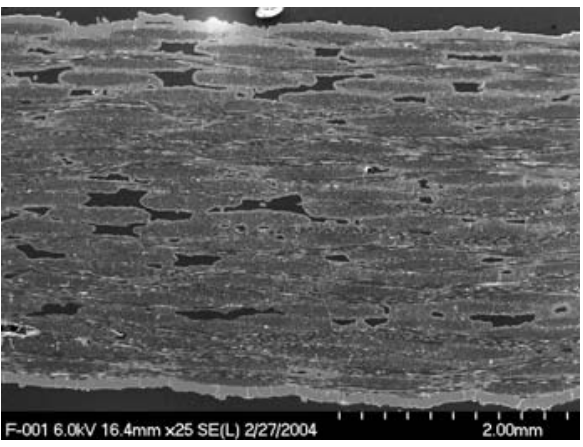

(b)

Figure 4. SEM micrographs at 25x for (a) fracture region and (b) center region indicating similar pore fractions (dark areas).

(a)
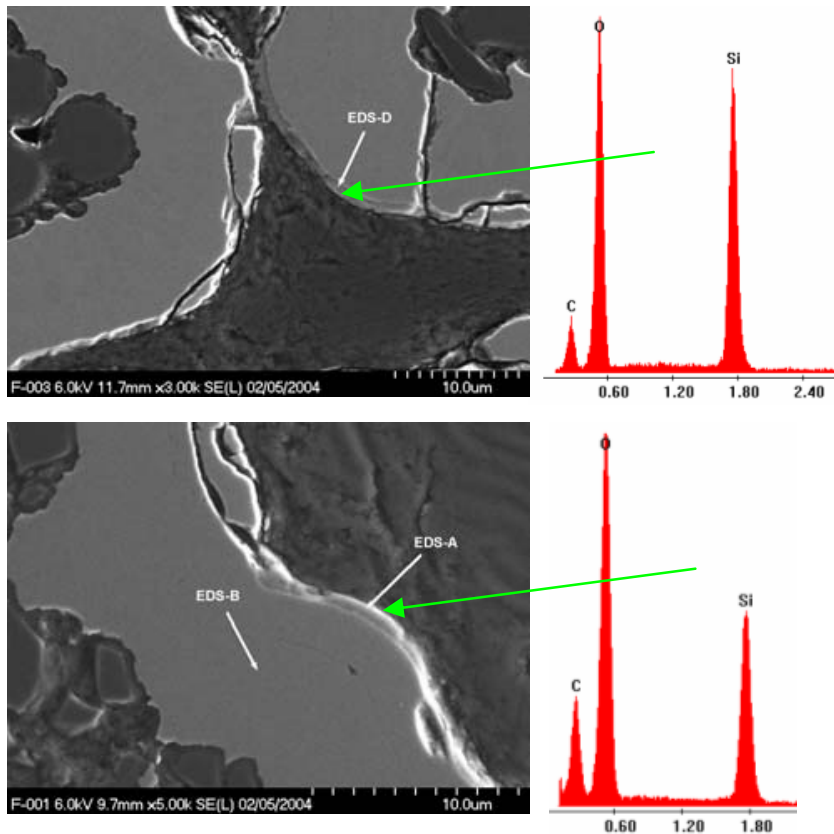

(b)

Figure 5. SEM micrographs at 5000x and Energy Dispersive Spectrometry results for (a) fracture region and (b) center region showing oxygen content (indicating oxidation) at edge of voids for both locations. 
The following observations are noted for $f_{c}$ (fig. 6) and $M_{0}$ (fig. 7), but are not readily explainable to date. In figure 6 , normalized $f_{c}$ line profiles appear to show a decreasing trend moving to the right in position for the 8 to 16 hour profiles. Average values calculated from all positions show an oscillating trend with increasing creep hours. In figure 7, normalized $M_{0}$ line profiles appear to become more uniform over time for the 8 to 16 hour profiles. Average values calculated from all positions show an oscillating trend with increasing creep hours. Elastic modulus values calculated from ramp up portions of the stress-strain curves also showed an oscillating trend with increasing creep hours as well (fig. 8).

$\langle t\rangle$ is plotted in figure 6 also and some correlation at most times appears to be seen between modulus and $\langle t\rangle$.

\section{Normalized Centroid Frequency vs. Position}

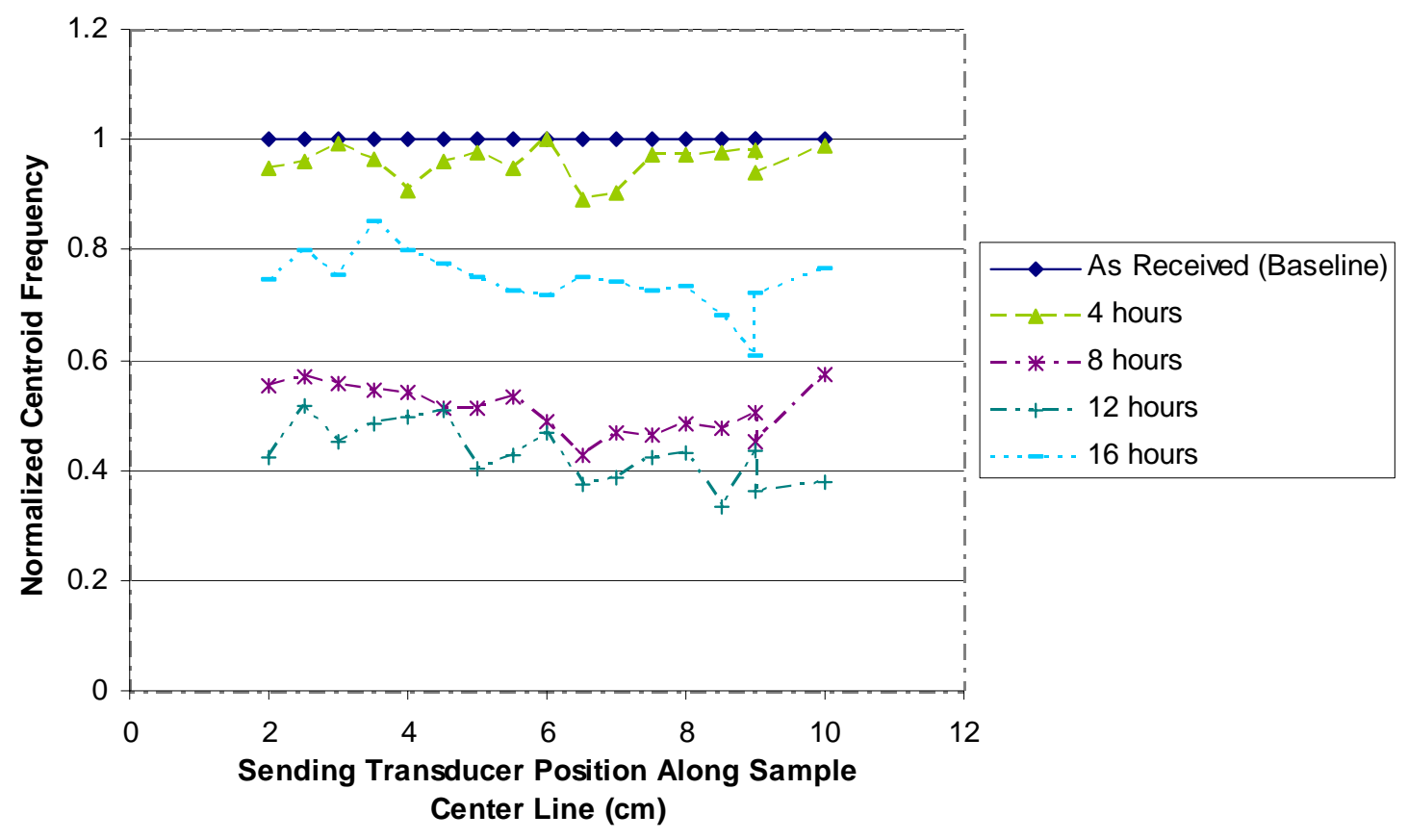

Figure 6. Normalized Centroid Frequency as a function of creep hours at locations along the center line of the sample. 
Normalized MO vs. Position

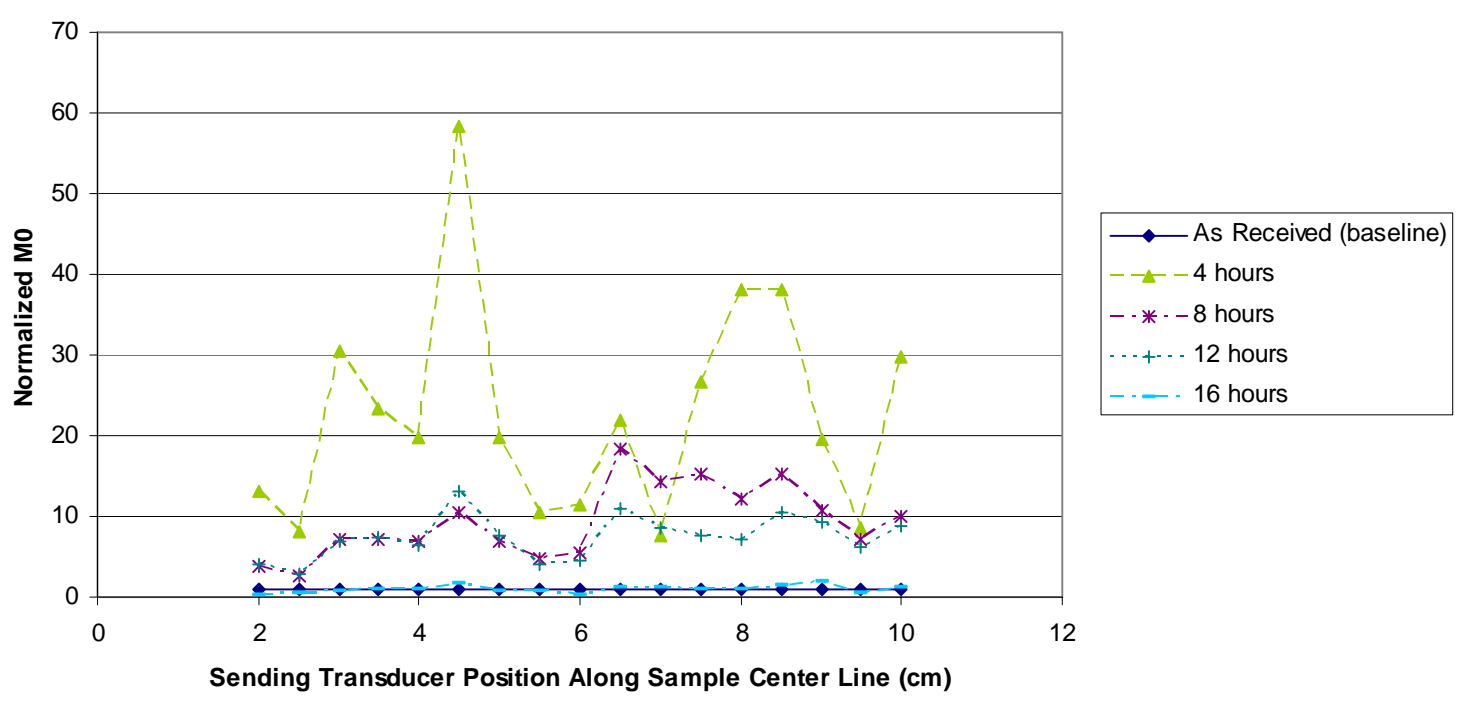

Figure 7. Normalized $M_{0}$ as a function of creep hours at locations along the center line of the sample.

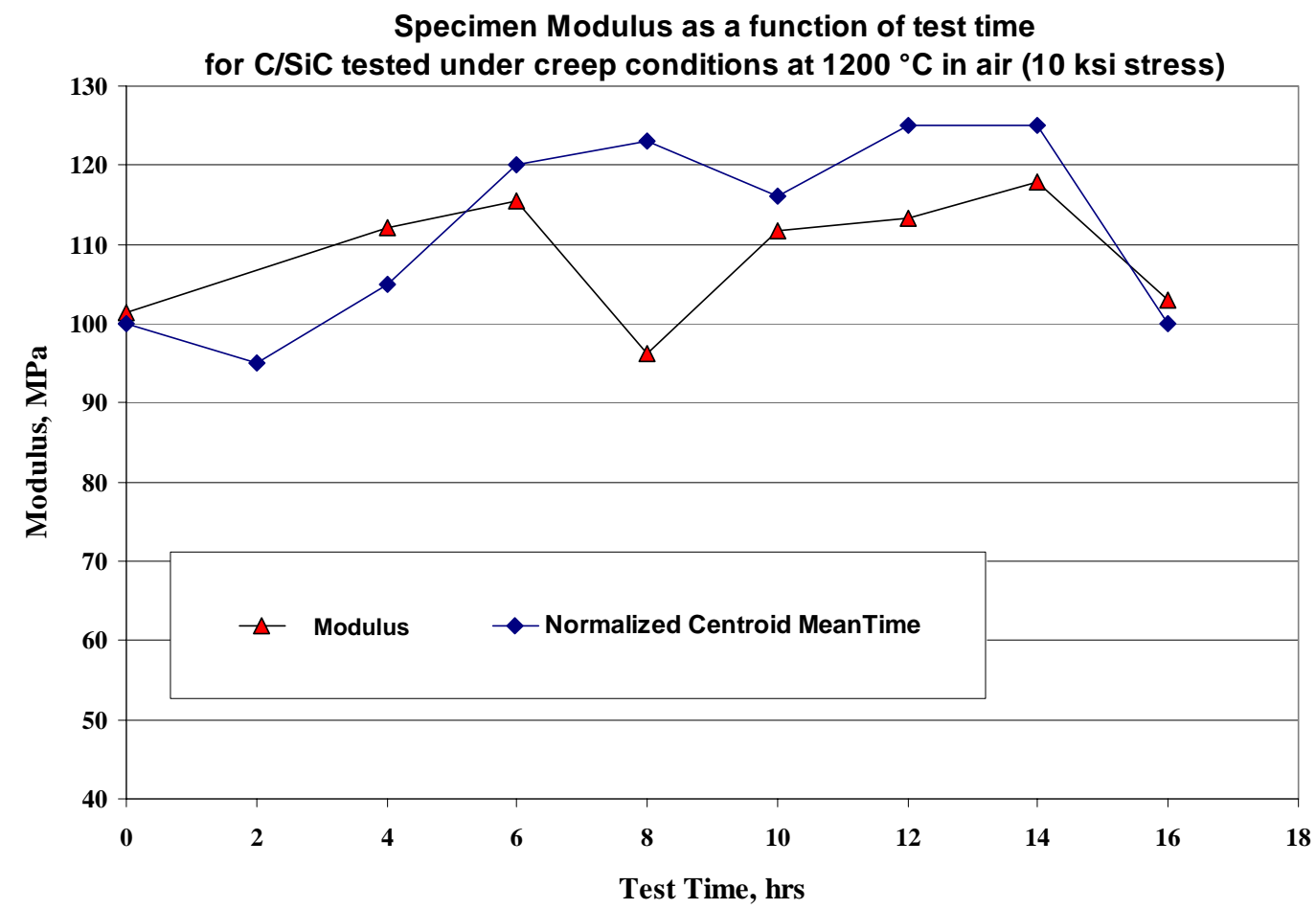

Figure 8. Specimen Modulus and normalized centroid mean time as a function of life fraction for the sample. 


\section{Imaging for Damage Visualization}

After 16 hours of creep testing of the sample, $M_{0}$ and ultrasonic decay initial energy $(K)$ clearly showed indications different from the rest of the sample at the $X=10$ to $11 \mathrm{~cm}$ location of the sample (whitish areas) (fig. 9). These indications are likely of the crack or open space (porous) nature as carbon fibers disappear due to oxidation. ${ }^{1-3}$ The critical points regarding these results include 1 ) these indications were not apparent by any means after 14 hours of creep-tensile testing indicating that major degradation likely occurred at the $X=10$ to $11 \mathrm{~cm}$ location between 14 and 16 hours of testing, 2) these indications were not apparent in optical or thermographic (amplitude- or derivative-based) images after 16 hours but were apparent in the guided wave images noted, and 3) the sample failed at the location of the indication 1.5 hours after being put back into the creep-tensile testing rig for another 2 hours of testing. However, as noted in the discussion above, from optical, SEM, and electron microprobe examinations of this sample, it was not possible to conclude that there was greater pore fraction or oxygen content at the eventual failure location versus that at the center region.

\section{- 14 hours}
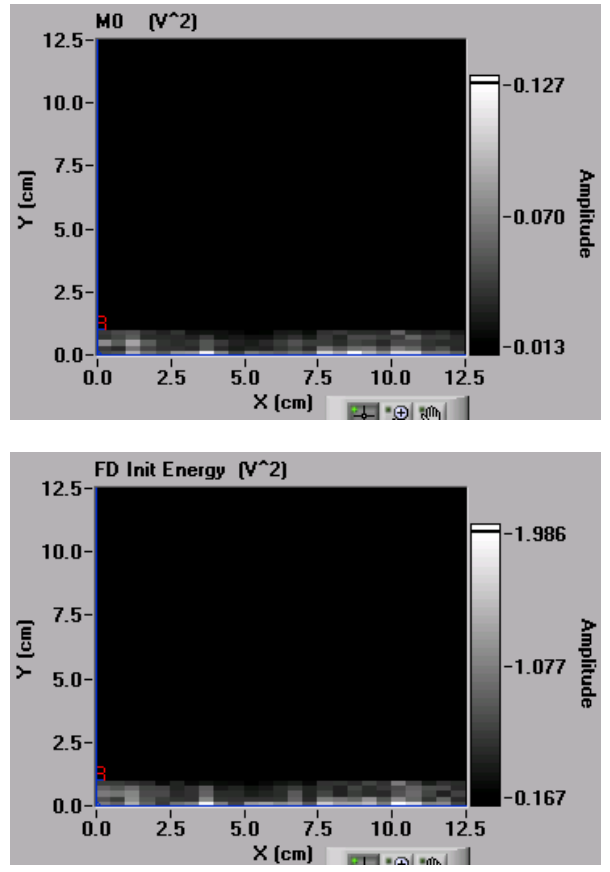

- 16 hours
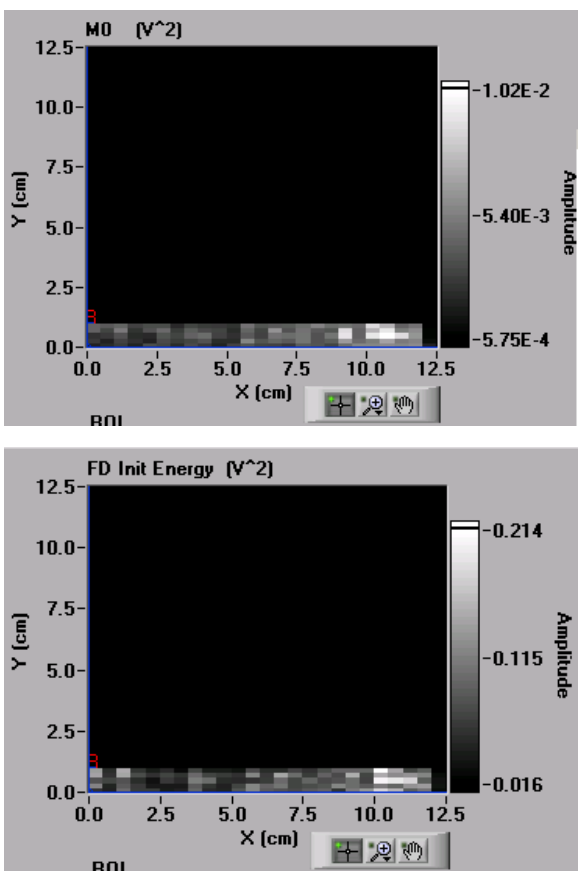

Figure 9. $M_{0}$ and Ultrasonic decay initial energy $(K)$ image for $\mathrm{C} / \mathrm{SiC}$ sample after 14 hours and after 16 hours of creep tensile testing. Note white indication in both 16 hour images at $X=10$ to $11 \mathrm{~cm}$ which was not apparent after 14 hours of testing. 


\section{Conclusions}

An ultrasonic guided wave scan system was used to nondestructively monitor damage over time and position in a C/enhanced $\mathrm{SiC}$ sample that was creep tested to failure at $1200{ }^{\circ} \mathrm{C}$ in air at a stress of $69 \mathrm{MPa}$ (10 ksi). The use of the guided wave scan system for mapping evolving oxidation profiles along the sample length (via porosity gradients resulting from oxidation) and predicting failure location was explored. The creep tests were interrupted for ultrasonic evaluation every two hours until failure which occurred at 17.5 cumulative hours. Several ultrasonic parameters were calculated and used to form line profiles and images of the sample. Centroid mean time appeared to exhibit an evolving spatial trend that would be consistent with nonuniform oxidation damage across the sample that has been previously reported. Specifically, normalized centroid mean time line profiles from 8 to 16 hours showed 20 to 40\% lower values at the center versus the thermal gradient regions possibly indicating a difference in porosity between these areas. However, in contrast to prior studies, optical, SEM, and electron microprobe examinations were not able to conclusively reveal pore fraction or oxygen content variations between center and failure regions. Zeroth moment and ultrasonic decay initial energy images clearly showed indications at the eventual failure location for the sample 1.5 hours prior to failure. A future article will discuss results from four other samples cut from the same block of material and identically-tested.

\section{References}

1. Verrilli, M.J., Kantzos, P.T., and Telesman, J., “Characterization of Damage Accumulation in a C/SiC Composite Subjected to Mechanical Loadings at Elevated Temperature," in the proceedings of Environmental, Mechanical, and Thermal Properties and Performance of Continuous Fiber Ceramic Composite (CFCC) Materials and Components, ASTM STP 1392, M.G. Jenkins, ed., American Society for Testing and Materials, West Conshohocken, PA, 2000.

2. Halbig, M.C. and Eckel, A.J., "Oxidation of Continuous Carbon Fibers Within a Silicon Carbide Matrix Under Stressed and Unstressed Conditions,” NASA/TM-2000-210224.

3. Halbig, M.C. and Brewer, D.N., "Degradation of Continuous Fiber Ceramic Matrix Composites Under Constant Load Conditions,” NASA/TM-2000-209681.

4. Verrilli, M.J., Calomino, A., and David Thomas, D.J. "Stress/Life Behavior of a C/SiC Composite in a Low Partial Pressure of Oxygen Environment Part I: Static Strength and Stress Rupture Database,” Ceramic Engineering and Science Proceedings, vol. 23, issue 3, pp. 435-442, 2002.

5. Halbig, M.C., "The Influence of Temperature, Stress, and Environment on the Oxidation and Life of C/SiC Composites," Ceramic Engineering and Science Proceedings, vol. 23, no. 3, pp. 419-426, 2002.

6. Kautz, H.E., “Acousto-Ultrasonics to Assess Material and Structural Properties,” NASA/CR-2002-211881.

7. Gyekenyesi, A.L., Kautz H.E., and Cao, W., "Damage Assessment of Creep Tested and Thermally Aged Udimet 520 Using Acousto-Ultrasonics,” NASA/TM-2001-210988.

8. Roth, D.J., Cosgriff, L.M., Martin, Verilli, and M.J., Bhatt, R.T., "Microstructural and Defect Characterization in Ceramic Composites Using an Ultrasonic Guided Wave Scan System,” NASA/TM-2003-212518.

9. Roth, D.J., Verrilli, M.J., Martin, R.E, Harmon, L.M., and Gyekenyesi, A.L., "Characterization of C/Enhanced SiC Composite Creep Damage Using An Ultrasonic Guided Wave Scan System,” Presentation and Proceedings of 27th Annual Conference on Composites, Materials, and Structures, Jan. 27-30, 2003, Radisson Resort at the Port, Cape Canaveral, Cocoa Beach, FL.

10. Rose, J.L., Ultrasonic Waves in Solids, Cambridge University Press, 1999, p. 17, figure 2-14.

11. Roth, D.J., Stang, D.B., Swickard, S.M., DeGuire, M.R., and Dolhert, L.E., "Review, Modeling and Statistical Analysis of Ultrasonic Velocity-Pore Fraction Relations in Polycrystalline Materials," Materials Evaluation, vol. 49, no. 7, July 1991, pp. 883-888. 


\section{Appendix Microprobe Analyses}

\section{Procedure}

Two metallographic mounts of the Carbon fiber/SiC matrix composite were submitted for microprobe analyses, identified as F001 (center-point) and F003 (fracture interface location). The primary purpose of this analysis was to compare the levels of oxidation between samples. The operating voltage of the probe was set to $15 \mathrm{Kv}$. Analytical x-ray measurements were performed at 20 nanoamps current. The X-ray lines and analyzing crystals utilized were; Oxygen Ka on synthetic LDE1, Carbon Ka on synthetic LDE2, and Si Ka on PET. Standards used were $\mathrm{SiO}_{2}$ for oxygen, and $\mathrm{SiC}$ for Silicon and carbon. The samples had previously been coated with a light layer of evaporated carbon for SEM work. Since carbon was not an issue, no corrections were made for this layer. A set of electron micrographs and x-ray distribution maps for each sample accompany this report.

Both SEI (secondary) and COMP (electron backscatter) images are included in the micrographs. Low energy secondary electrons form SEI images, which are created near the surface and carry topographic information. Higher energy backscattered electrons form COMP images and escape from a greater depth within the sample. They are formed by the interaction of the electron beam with the sample atoms and therefore the signal carries information about the mean atomic number of the phase or phases. BSE images can also carry information about the orientation crystalline phases. Higher atomic number phases become progressively lighter on the black and white scale. Crystalline orientations will show various degrees of gray level.

Each of the x-ray distribution maps are a guide net series composed of four individual maps. Each quadrant is composed of 800 by 800 pixels. The x-ray data for each point was obtained by moving the stage in 1.0 micron increments and the dwell time for each point was $2 \mathrm{msec}$. These maps are quantitative to a degree - the weight percentage of each element is illustrated by a false color indicator on the side of each map. These values cannot be considered optimum since the location of each point is arbitrarily a function of the starting location. In the finer microstructures and phases, the volume of excitation will be large enough to overlap adjacent phases and influence to the x-ray signal. This interaction will either intensify or diminish the $\mathrm{x}$-ray signal depending on the compositions. Larger volume phases will generally show the correct values since this interaction effect is not present except at boundaries.

\section{Results}

Two low magnification BSE images from each sample have been combined to show the complete cross section. A comparison of these montages illustrates that the inter-toe, CVI (chemical vapor infiltration) silicon carbide becomes progressively thinner as one free surface of the composite is approached in sample F001 (montage A). In contrast, this thickness of this component illustrates a somewhat Gaussian characteristic in sample F003, progressively becoming thinner as the center of the composite is approached from either free surface. The silicon carbide which is greater than $\sim 25$ microns in thickness exhibits a distinctly layered microstructure in the BSE images for both samples. The mottled appearance of SiC in the surface layer adjacent to the void walls near the surface and on the surface is characteristic of CVI re-crystallization (F001-007, F001-008, F001-009); (F003-006,F003-007). The Interior CVI SiC which lines the void walls is also layered but does not exhibit the coarsely crystalline microstructure of the surface material (F001-010, F001-011); (F003-008, F003-009). These micrographs illustrate that in these voids is where the silicon oxide layer forms. 


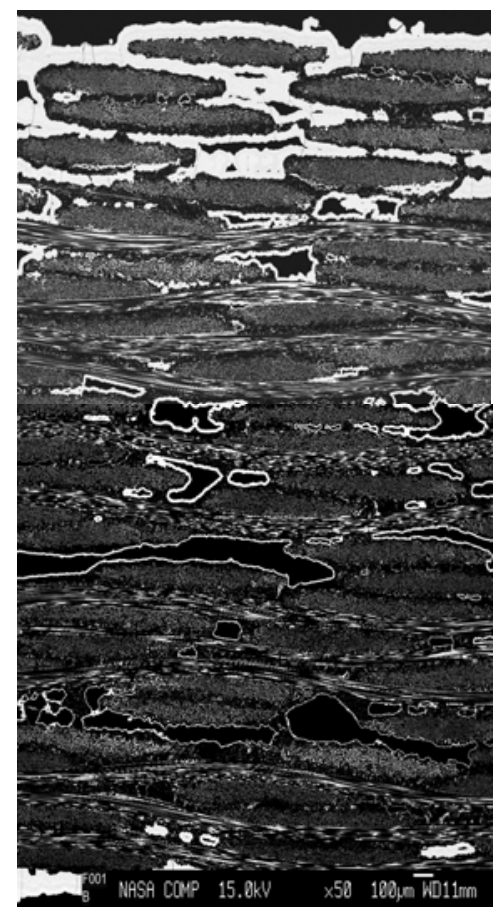

(a)

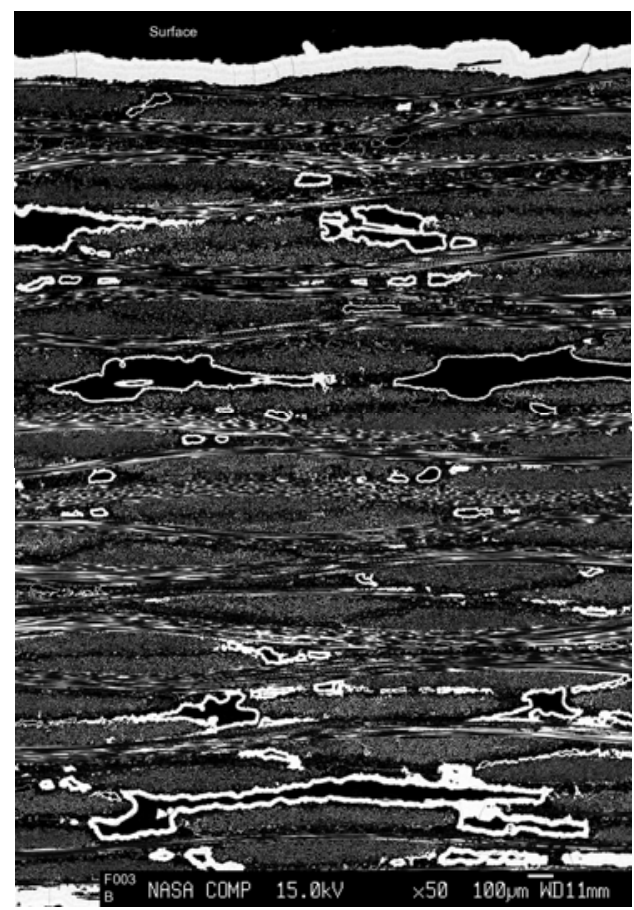

(b)

Figure A1. Backscatter electron montage images at low magnification obtained from electron microprobe analysis of sample 5 cross-sections at (a) center region (F001) and (b) fracture surface (F003).

There are one set of X-ray maps for sample F001 and two sets for F003. The set for F001 illustrates carbon, silicon, oxygen and the BSE image for one half of the cross section. The oxygen map indicates that at a depth of $\sim 800$ microns the oxide layer in the voids is present. I found it to be present to within 250 microns of the opposing surface. It can be seen that in all the Si maps, there is concentration variable between the $\mathrm{SiC}$ coated fibers and the CVI layers, when in fact it should be the same. This is an example of the X-ray interaction of the carbon fiber phase and the relatively thin $(0.05 \mu \mathrm{m}) \mathrm{SiC}$ on the fiber surface (F001-017 and F003-010. Two sets of maps are provided for sample F003 which show the complete cross section. The oxygen maps illustrate the development of an oxide layer in the voids at a depth of around 600 microns where the CVI thickness is $\sim 20$ to 25 microns. As in F001, this oxide is present in the voids almost throughout the remaining thickness. It can be seen that the oxygen signal in some cases seems much stronger on the lower $\mathrm{X}$ void surface. This is a topographic effect in that the oxygen spectrometer is located at the top of the map (north), and there has been some rounding from the polishing operation at the SiC-epoxy interface in void areas. This can effectively block some of the oxygen signal on the upper $\mathrm{X}$ void surface. 


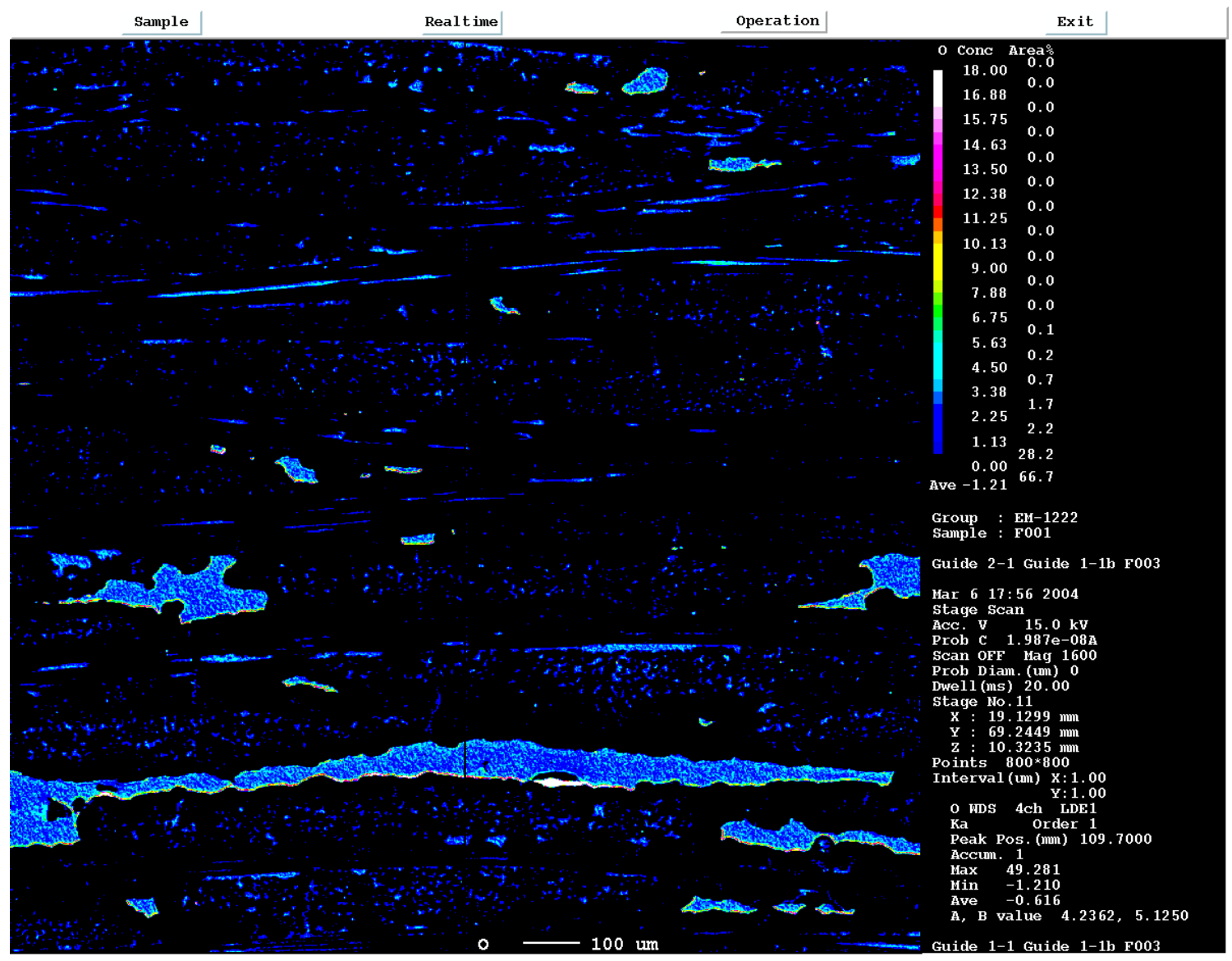

(a)

Figure A2. Oxygen maps obtained from electron microprobe analysis of sample 5 cross-sections at (a) fracture surface and (b) center region. 


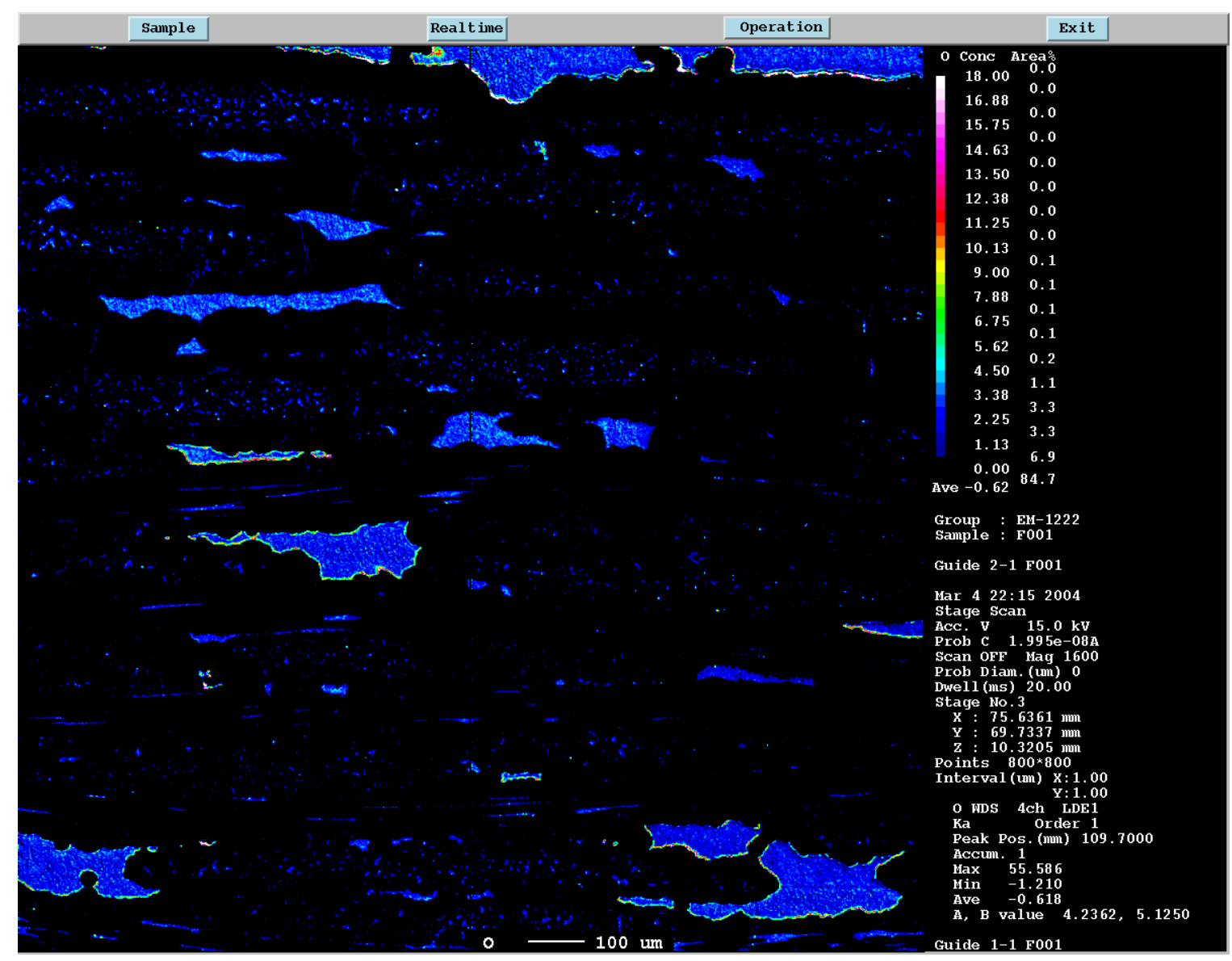

(b)

Figure A2. Concluded. 



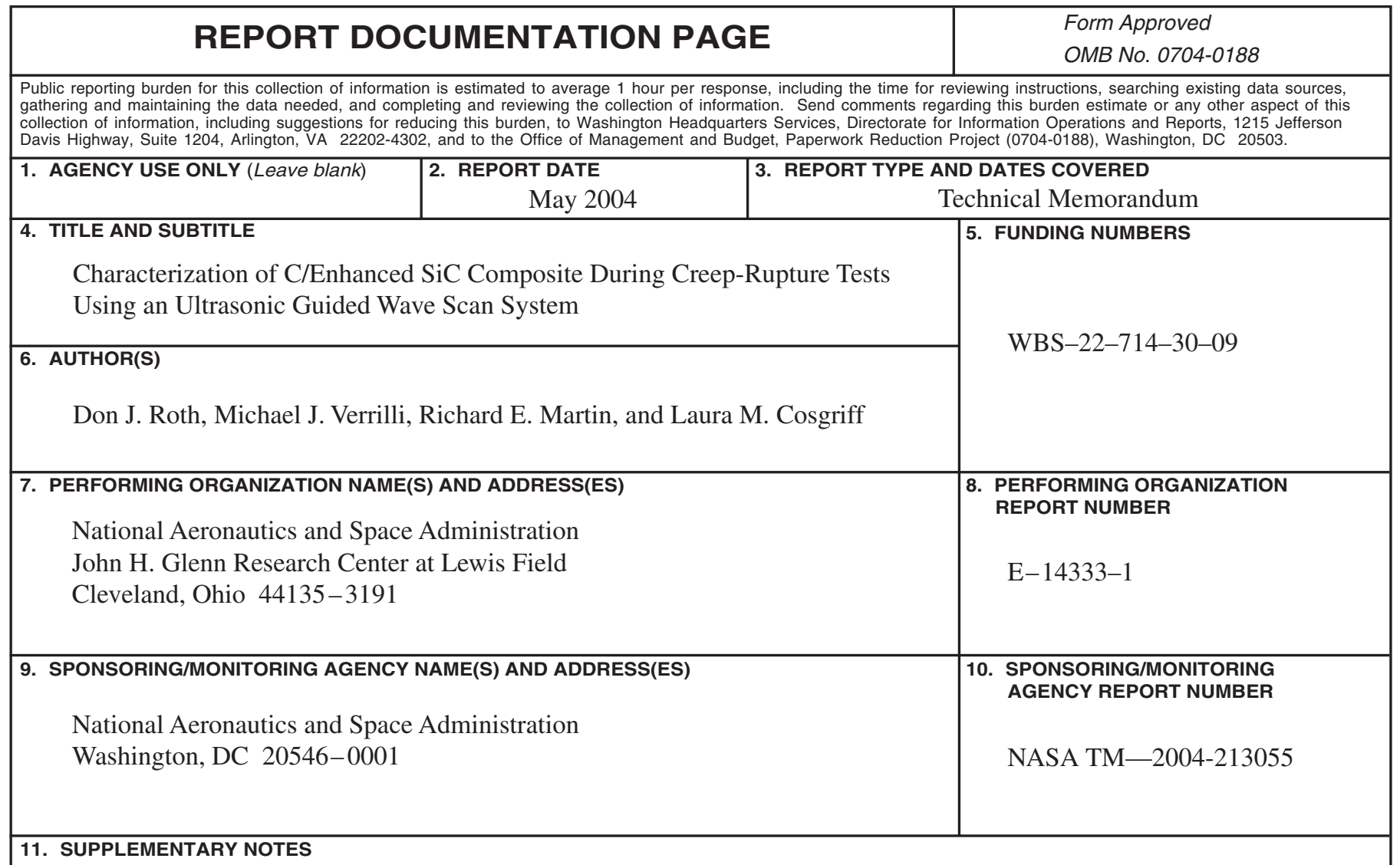

Prepared for the 28th Annual International Conference and Exposition on Advanced Ceramics and Composites sponsored by the American Ceramic Society, Cocoa Beach, Florida, January 25-30, 2004. Don J. Roth and Michael J. Verrilli, NASA Glenn Research Center; and Richard E. Martin and Laura M. Cosgriff, Cleveland State University, Cleveland, Ohio 44115. Responsible person, Don J. Roth, organization code 5520, 216-433-6017.

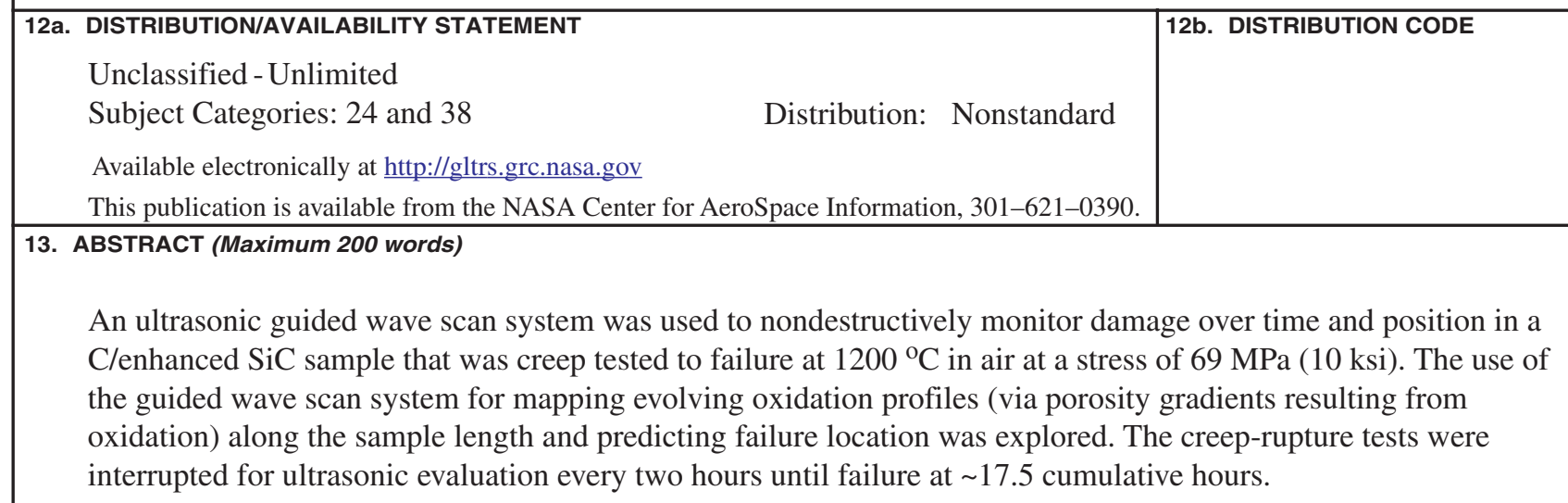

\begin{tabular}{|c|c|c|c|}
\hline \multicolumn{3}{|l|}{ 14. SUBJECT TERMS } & 15. NUMBER OF PAGES \\
\hline \multicolumn{3}{|c|}{ Guided waves; Composites; Ceramics; Scanning; C/SiC; Oxidation; Creep } & 20 \\
\hline $\begin{array}{l}\text { 17. SECURITY CLASSIFICATION } \\
\text { OF REPORT }\end{array}$ & $\begin{array}{l}\text { 18. SECURITY CLASSIFICATION } \\
\text { OF THIS PAGE }\end{array}$ & $\begin{array}{l}\text { 19. SECURITY CLASSIFICATION } \\
\text { OF ABSTRACT }\end{array}$ & 20. LIMITATION OF ABSTRACT \\
\hline Unclassified & Unclassified & Unclassified & \\
\hline \multicolumn{3}{|l|}{ NSN 7540-01-280-5500 } & $\begin{array}{l}\text { andard Form } 298 \text { (Rev. 2-89) } \\
\text { scribed by ANSI Std. Z39-18 } \\
3-102\end{array}$ \\
\hline
\end{tabular}



